\title{
INTERAÇÕES INTERMOLECULARES E O FENÔMENO DA SOLUBILIDADE: EXPLICAÇÕES DE GRADUANDOS EM QUÍMICA
}

\author{
Marianna M. Junqueira ${ }^{a}$ e Flavio A. Maximiano ${ }^{\mathrm{b}, *, 10}$ \\ aDepartamento de Química, Universidade Federal de Lavras, 37200-000 Lavras - MG, Brasil \\ bDepartamento de Química Fundamental, Instituto de Química, Universidade de São Paulo, 05508-000 São Paulo - SP, Brasil
}

Recebido em 27/05/2019; aceito em 22/08/2019; publicado na web em 27/11/2019

\begin{abstract}
INTERMOLECULAR INTERACTIONS AND THE SOLUBILITY PHENOMENON: EXPLANATIONS OF CHEMISTRY STUDENTS. The present study investigated the use of intermolecular interaction concepts by freshman chemistry students during general chemistry classes, explaining some of the solubility phenomenon. For this purpose, classes on the topic in question were monitored and two tests were asking for explanations for the difference in solubility of oxygen and carbon dioxide in water and in perfluorocarbons and oxygen in fresh or salt water. Students also made graphic representations showing the water - oxygen molecules interactions. An analysis of the data demonstrated that several students had difficulties in correctly identifying that intermolecular interactions are involved in these systems. The concept of polarizability, fundamental in these systems, was rarely used in their explanations. The answers also indicated extensive use of the "like dissolves like" rule to explain solubility rather than using a complete description of the interactive processes involved. Most of the students' explanations suggest an understanding of the knowledge as data or fact reproducing information and ideas without an effective use and understanding of the chemical concepts.
\end{abstract}

Keywords: intermolecular interactions; solubility; higher education; conceptual learning.

\section{INTRODUÇÃO}

Ensinar e aprender conceitos científicos têm sido um dos desafios para docentes e estudantes e uma preocupação central na área de ensino de ciências. Dentre os conteúdos conceituais fundamentais para o aprendizado da Química destaca-se o de interações intermoleculares, que pode ser considerado como um dos conceitos centrais e estruturais dessa Ciência, por permitir a explicação e entendimento da natureza da matéria, suas transformações e propriedades, objeto que define a própria ciência Química. ${ }^{1} \mathrm{O}$ conhecimento de como se dão as interações entre moléculas é fundamental para a compreensão de diversos fenômenos, pois explica propriedades como solubilidade, volatilidade, ponto de fusão e ponto de ebulição, entre outras. Por consequência, o tema é transversal no currículo de um curso de química, estando presente de maneira explícita ou implícita nas diversas disciplinas que o compõem, constituindo-se num conceito mais geral ou um verdadeiro princípio que estrutura o conhecimento químico. ${ }^{2}$ Assim, sua profunda e correta compreensão é fundamental na formação do químico, seja para a atuação deste como docente na educação básica ou superior, em indústrias ou pesquisas acadêmicas.

Ao pensar em interações intermoleculares, logo ocorre a associação às forças de atração e repulsão entre as moléculas que compõem um determinado sistema. Todavia, o que acontece, frequentemente, é que os estudantes confundem as interações intermoleculares com as ligações químicas, também conhecidas como interações intramoleculares. ${ }^{3,4}$ Assim, um passo fundamental na diferenciação desses conceitos é a compreensão de que enquanto as ligações químicas unem os átomos em uma molécula e constituem a base para a definição das propriedades químicas, as interações intermoleculares influenciam as propriedades físicas da matéria. ${ }^{5}$

Na literatura há um número expressivo de pesquisas sobre concepções alternativas para ligações iônica, covalente e metálica, entretanto, os estudos sobre estas concepções para interações intermoleculares ainda não são tão expressivos, como para outros temas de ensino de

\footnotetext{
*e-mail: famaxim@iq.usp.br
}

química. ${ }^{6,7}$ No entanto, alguns estudos apontam que muitos estudantes da educação básica possuem a ideia de que as interações intermoleculares são mais fortes do que as intramoleculares, e apresentam grande dificuldade na compreensão da relação entre as interações intermoleculares e as propriedades físicas. ${ }^{3,8}$ Peterson mostrou que até mesmo no ensino universitário são encontradas concepções de que as interações intramoleculares são rompidas durante mudanças de estado, ao invés das interações intermoleculares. ${ }^{9}$ Em outra investigação, Coll e Taylor relataram que estudantes dos diferentes níveis de escolaridade imaginavam que as interações intermoleculares eram influenciadas pela gravidade. ${ }^{10}$

Nesse contexto, destacamos a formação de uma solução, fenômeno no qual ocorre a interação entre um soluto e um solvente. Quantitativamente a solubilidade pode ser definida como a quantidade de soluto que pode ser dissolvido em uma determinada quantidade de solvente, em condições de equilíbrio. ${ }^{11}$ Qualitativamente esse fenômeno pode ser explicado em nível submicroscópico considerando-se as intensidades relativas de interações atrativas entre as partículas de soluto e solvente. Inicialmente devem-se levar em conta as interações atrativas entre as partículas do próprio soluto e interações atrativas entre as partículas do próprio solvente que, durante o processo de dissolução, vão se romper e originar interações entre moléculas do soluto e do solvente. Além da determinação dos tipos de interações é necessário fazer um balanço do gasto energético para determinar se o processo é favorecido de maneira que o ganho energético obtido nas interações soluto-solvente deve sobrepor ao consumo necessário para romper as interações soluto-soluto e solvente-solvente. ${ }^{11}$ Para isso, o conhecimento dos tipos de interações intermoleculares envolvidos, bem como o valor energético relativo das mesmas, permite fazer previsões ou explicar diferenças de solubilidade de maneira qualitativa.

Estudos que investigam as concepções ou dificuldades sobre o tema interações intermoleculares e especificamente como graduandos em química utilizam os conhecimentos conceituais presentes nessa temática para explicar diferentes fenômenos ainda são escassos, especialmente no cenário brasileiro. Tendo em vista essa carência, o presente trabalho investigou o uso das interações intermoleculares 
envolvidas no fenômeno da solubilidade por graduandos em química cursando uma disciplina de Química Geral, com o objetivo de elencar as principais características das explicações destes graduandos e, a partir daí, obter subsídios para uma reflexão sobre o processo de ensino desse tema.

\section{METODOLOGIA}

Os dados foram coletados na disciplina de Química Geral I, oferecida a ingressantes no período integral de um curso de graduação em Química de uma universidade pública do estado de São Paulo. O programa da disciplina contemplou noções sobre a origem dos elementos, modelos atômicos, partículas atômicas fundamentais, estequiometria, estrutura eletrônica: átomo de Bohr e ondas eletromagnéticas, princípios da mecânica quântica e orbitais, ligação covalente: estruturas de Lewis, teoria da ligação de valência e teoria dos orbitais moleculares, geometrias moleculares e a teoria VSEPR, princípios da estrutura do estado sólido, teorias de bandas, estrutura molecular e interações intermoleculares, ligação iônica e terminou com os compostos de coordenação. O tema interações intermoleculares foi abordado durante quatro aulas de duração aproximada de 1 h 40 min. O fenômeno da solubilidade foi usado como exemplo nas duas primeiras aulas ao longo das explicações das interações: ligação de hidrogênio (sistema: metanol e água), dipolo-dipolo induzido (sistema: oxigênio e água) e íon-dipolo (sistema: cloreto de sódio e água).

Durante a disciplina foram aplicadas duas questões, abordando a solubilidade de gases apolares, em momentos distintos do semestre letivo (Quadro 1). A primeira questão (Q1) foi elaborada pelo grupo de pesquisa, sem intervenção do docente, e objetivava verificar se os estudantes empregavam e como empregavam as interações intermoleculares para explicar a solubilidade do gás oxigênio em água. A fim de revelar a compreensão do processo de interação oxigênio-água em nível submicroscópico, a questão também pedia representar o fenômeno através de desenhos. A segunda questão (Q2), elaborada pelo docente da disciplina, estava inserida na avaliação final da mesma. Foi dividida em duas partes, a primeira solicitava explicações sobre a diferença de solubilidade dos gases oxigênio e dióxido de carbono em perfluorocarbonos e em água, a segunda parte perguntava se o gás oxigênio é mais solúvel em água pura ou água salgada, pedindo também uma justificativa para a resposta. A similaridade das questões possibilitou comparações entre as respostas registradas em momentos distintos da instrução. 45 e 53 estudantes, que tiveram sua identidade preservada, responderam Q1 e Q2 respectivamente.

As quatro aulas sobre o tema, anteriormente descritas, foram gravadas em vídeo e transcritas em sua íntegra. As transcrições das aulas também constituem parte dos dados analisados, uma vez que as falas do professor foram confrontadas com as respostas.

Explicações sobre a solubilidade do gás oxigênio em água foram solicitadas por se tratar de um importante fenômeno para a manutenção da vida aquática; fato que ocorre em nível submicroscópico devido à formação de um dipolo induzido. As moléculas de gás oxigênio, ao se aproximarem das moléculas de água, instantaneamente têm a formação de momentos de dipolo induzidos em suas moléculas, permitindo a solubilidade. Mas, esse fenômeno ocorre em uma pequena extensão, o que causa a baixa solubilidade. Para o oxigênio verifica-se a 1 atm e $25^{\circ} \mathrm{C}$ uma solubilidade de 8,11 $\mathrm{mg} \mathrm{L}^{-1} .^{13}$

De posse das respostas, essas foram digitalizadas, lidas e categorizadas seguindo o esquema proposto por Bardin para a análise de conteúdo. ${ }^{14}$ As categorias de análise foram construídas levando-se em conta as explicações apresentadas para cada item das questões, desse modo, as respostas foram lidas algumas vezes e agrupadas em categorias pela autora do presente trabalho. Em seguida, as respostas e categorias foram apresentadas aos demais membros do grupo de pesquisa para validação. Após a categorização dos itens das questões organizou-se um quadro resumo com as características mais recorrentes das explicações obtidas. Os dados obtidos foram analisados e cruzados com as transcrições das aulas e com a forma como o conteúdo é apresentado nos livros didáticos sugeridos como referência de estudo para a disciplina, permitindo discutir possíveis relações entre as dificuldades apresentadas pelos estudantes e a forma como o conteúdo costuma ser apresentado.

Quadro 1. Questões aplicadas na disciplina de Química Geral I ${ }^{12}$

\begin{tabular}{|c|l|l|}
\hline Momento de aplicação & Questão \\
\hline Questão solicitada logo após a instrução do tema. & $\begin{array}{l}\mathrm{O}_{2} \text { é uma substância apolar. Em contrapartida sabemos que a água é uma substância polar. Diante } \\
\text { deste fato como podemos explicar a solubilidade do gás oxigênio em água? Faça um desenho que } \\
\text { represente microscopicamente esse fenômeno. }\end{array}$ \\
\hline $\begin{array}{l}\text { Perfluorocarbonos como a perfluorodecalina e perflobron têm a capacidade de dissolver grandes } \\
\text { quantidades de } \mathrm{O}_{2}(40-50 \mathrm{~mL} / 100 \mathrm{~mL}) \text { e } \mathrm{CO}_{2}(250 \mathrm{~mL} / 100 \mathrm{~mL}) \text { comparativamente à água }\left(\mathrm{O}_{2} \text { : }\right. \\
2,5 \mathrm{~mL} / 100 \mathrm{~mL} ; \mathrm{CO}_{2}: 80 \mathrm{~mL} / 100 \mathrm{~mL} \text { nas mesmas condições de pressão e temperatura. Devido } \\
\text { a solubilidade destes gases nos perfluorocarbonos e graças à sua estabilidade estes compostos são } \\
\text { modelos do desenvolvimento do "sangue artificial" }\end{array}$ & $\begin{array}{l}\text { a) Explique porque } \mathrm{O}_{2} \text { e } \mathrm{CO}_{2} \text { se dissolvem em água e porque a solubilidade é maior nos perfluoro- } \\
\text { carbonos. }\end{array}$
\end{tabular}




\section{RESULTADOS}

\section{Explicações para a solubilidade do gás oxigênio em água}

São apresentadas as respostas para Q1 e para o item a da Q2, comparando as explicações dadas em dois momentos distintos, ao responderem sobre a possibilidade de oxigênio gasoso ser dissolvido em água. Estando o oxigênio em estado gasoso, suas moléculas não apresentam interações intermoleculares entre si, enquanto as moléculas da água interagem entre si através de ligação de hidrogênio. No processo de dissolução algumas ligações de hidrogênio são rompidas. Como a molécula de oxigênio é polarizável, pode interagir com moléculas de água, uma vez que, sendo a água uma molécula polar, pode induzir na molécula de oxigênio um momento de dipolo. Uma vez polarizada, essa molécula de oxigênio pode interagir com outra molécula de água. Esse tipo de interação é denominado dipolo-dipolo induzido. Essa é uma explicação mais completa que dá ênfase ao processo, ressaltando as propriedades polarizabilidade e momento de dipolo como centrais para que o processo se dê desta maneira. Uma resposta desse tipo indicaria uma compreensão conceitual mais completa. No entanto, ninguém respondeu de forma tão completa, o que é esperado uma vez que sendo estudantes do primeiro semestre do curso de Química, não se tem expectativa de que eles tenham tal domínio conceitual. Foram consideradas corretas as respostas que afirmavam simplesmente que a solubilidade se dá devido às interações do tipo dipolo-dipolo induzido. É válido destacar que o mais importante aqui é analisar o que e como respondem os estudantes.

As explicações apresentadas nas questões 1 e 2 foram categorizadas considerando o tipo de interação atribuído ao fenômeno e sistematizadas no Quadro 2. Dos 45 estudantes que responderam à questão 1 nota-se que dez (23\%) deixaram suas respostas em branco sugerindo a existência de dificuldades para explicar o fenômeno em estudo. Por outro lado, o número de respostas em branco foi reduzido na questão 2 (4\%) provavelmente por estar inserido em uma avaliação que compunha a nota final da disciplina.

Além das respostas em branco dez estudantes, tanto na questão 1 (22\%) quanto na questão $2(19 \%)$ responderam de forma totalmente incorreta (Quadro 2). O número de respostas incorretas também diminuiu ao comparar as explicações dadas a questão 1 e depois a questão 2. Dentre os erros mais comuns encontram-se explicações que consideram a ocorrência de ligações de hidrogênio entre o gás oxigênio e a água ( $11 \%$ das respostas na questão $1,15 \%$ na questão 2). Desses, apenas um manteve esse tipo de resposta para as duas questões, os demais (4) mudaram sua resposta na segunda avaliação, acertando a explicação. Dos oito que cometeram esse erro na questão 2, cinco haviam deixado a questão 1 em branco e dois não haviam participado da aplicação do primeiro questionário. Respostas típicas representando esse tipo de erro são apresentadas a seguir:

"É possível solubilizar o gás oxigênio em água por causa da ligação de hidrogênio que ocorre entre $\mathrm{H}_{2} \mathrm{O}$ (l) e $\mathrm{O}_{2}$ (g)." (A13 - Q1)

"Com a formação das pontes de hidrogênio, o $\mathrm{O}_{2}$ se solvata entre as moléculas de $\mathrm{H}_{2} \mathrm{O}$.” (A25 - Q1)

Ainda na questão 1, dois responderam que ocorre uma quebra das moléculas de oxigênio para a formação de íons permitindo a solubilidade. Nesse caso, é nítida uma transferência direta do conceito de dissociação iônica (solubilidade de compostos iônicos) para o caso em estudo. A ocorrência da ionização ou dissociação foi tratada como fenômeno decorrente da solubilização, ou seja, para que haja dissolução é necessário a ionização ou dissociação
Quadro 2. Categorias para o fenômeno de dissolução de gás oxigênio em água

\begin{tabular}{|l|l|c|c|}
\hline \multirow{2}{*}{ Categorias } & \multicolumn{2}{|c|}{$\begin{array}{c}\text { Número de } \\
\text { estudantes }\end{array}$} \\
\cline { 3 - 4 } & \multicolumn{2}{|c|}{ Q1 } & Q2 \\
\hline $\begin{array}{l}\text { Respostas } \\
\text { consideradas } \\
\text { corretas }\end{array}$ & $\begin{array}{l}\mathrm{O}_{2} \text { e } \mathrm{H}_{2} \mathrm{O} \text { interagem através da } \\
\text { interação do tipo dipolo-dipolo } \\
\text { induzido. }\end{array}$ & $25(56 \%)$ & $41(77 \%)$ \\
\hline \multirow{5}{*}{$\begin{array}{l}\text { Respostas } \\
\text { consideradas } \\
\text { incorretas }\end{array}$} & $\begin{array}{l}\mathrm{O}_{2} \text { e } \mathrm{H}_{2} \mathrm{O} \text { interagem através de } \\
\text { ligação de hidrogênio. }\end{array}$ & $5(11 \%)$ & $8(15 \%)$ \\
\cline { 2 - 4 } & $\begin{array}{l}\text { Considera que } \mathrm{O}_{2} \text { já apresenta } \\
\text { dipolos induzidos (como no } \\
\text { caso do } \mathrm{O}_{2} \text { líquido) que irão } \\
\text { interagir com o dipolo da } \mathrm{H}_{2} \mathrm{O} .\end{array}$ & $1(2 \%)$ & $1(2 \%)$ \\
\cline { 2 - 4 } & $\begin{array}{l}\text { A molécula de } \mathrm{O}_{2} \text { sofre ioniza- } \\
\text { ção permitindo a solubilidade } \\
\text { em água. }\end{array}$ & $2(4 \%)$ & -- \\
\cline { 2 - 4 } & $\begin{array}{l}\mathrm{O}_{2} \text { ocupa espaços entre as } \\
\text { moléculas de água permitindo } \\
\text { a solubilidade. }\end{array}$ & $1(2 \%)$ & -- \\
\cline { 2 - 4 } & $\begin{array}{l}\mathrm{O}_{2} \text { e } \mathrm{H}_{2} \mathrm{O} \text { interagem através } \\
\text { de dipolo induzido-dipolo in- } \\
\text { duzido. }\end{array}$ & $1(2 \%)$ & -- \\
\cline { 2 - 4 } & $\begin{array}{l}\text { Ocorre uma reação química } \\
\text { entre } \mathrm{O}_{2} \text { e } \mathrm{H}_{2} \mathrm{O} .\end{array}$ & -- & $1(2 \%)$ \\
\hline Em branco & \begin{tabular}{l} 
Q \\
\hline
\end{tabular} & $10(23 \%)$ & $2(4 \%)$ \\
\hline
\end{tabular}

como já foi verificado no estudo de Souza e Cardoso (2009) realizado com pós-graduandos em química. ${ }^{15}$ Uma resposta considerou a solubilidade devido à existência de interações dispersivas de London entre a água e o gás oxigênio. Em uma outra resposta não foram apresentados argumentos envolvendo as interações, mas que o oxigênio ocupa espaços entre as moléculas de água. Explicações envolvendo a ocupação de espaços estão presentes em respostas que não conseguem compreender que há interações entre soluto e solvente. Assim, o solvente, no caso a água, não participa diretamente do processo de solubilização. ${ }^{16}$ Tal concepção já foi relatada em estudos com estudantes do ensino médio que têm dificuldade em perceber as interações entre soluto e solvente mesmo quando deixam explicito que o processo ocorre entre as duas substâncias. ${ }^{16}$ Por fim, um estudante simplesmente respondeu tanto na questão 1 como na questão 2 que o gás oxigênio se dissolve em água porque apresenta um dipolo induzido e um outro que não participou da aplicação da questão 1 citou que a solubilidade é devido a ocorrência de uma reação química, mas não explicitou qual o tipo de reação.

Tanto na questão 1 como na questão 2 a maioria dos estudantes respondeu as perguntas de forma satisfatória, considerando ao menos a existência de interações dipolo-dipolo induzido no processo de solubilização do gás oxigênio em água, ou seja, foram consideradas corretas mesmo as respostas que não apresentaram uma explicação completa do processo de interação envolvido na solubilização. Nota-se um aumento de $56 \%$ para $77 \%$ de respostas consideradas corretas entre as duas questões aplicadas em momentos distintos na disciplina. No entanto, uma análise mais minuciosa permite agrupar estas respostas em três categorias da mais simples à mais completa.

Dentro dessas respostas há algumas que simplesmente citam o tipo da interação em si como justificativa para a solubilidade (1 na questão 1 e 6 na questão 2).

"Os gases se dissolvem em água devido a interações dipolodipolo induzido das moléculas de água com as dos gases $\left(\mathrm{O}_{2}\right.$, $\left.\mathrm{CO}_{2}\right)$." (A38 - Q2) 
Boa parte dos estudantes ( 17 - $42 \%$ na questão 1 e $14-26 \%$ na questão 2) justificam a dissolução seguindo um raciocínio mais completo: a água é polar, os gases são apolares, para que ocorra a dissolução dos gases em água, essa deve induzir "uma polaridade" nas moléculas dos gases. Nessas respostas, percebe-se uma ênfase na polaridade da água. Nesses casos não foi citado o conceito de polarizabilidade (ou distorção da nuvem eletrônica) das moléculas de soluto.

"A polaridade da água "induz" um polo na molécula de oxigênio, essa polarização momentânea faz com que o gás oxigênio possa ser solubilizado em água." (A6 - Q1)

" $\mathrm{O}_{2}$ e $\mathrm{CO}_{2}$ dissolvem-se em água pois, mesmo sendo apolares, a $\mathrm{H}_{2} \mathrm{O}$ (que é polar) induz nessas moléculas um dipolo instantâneo, tornando-se um pouco polares para dissolução, pois semelhante dissolve semelhante." (A48 - Q2)

Por outro lado, poucos estudantes (6 na questão 1 - 13\% e 14 - $26 \%$ na questão 2) apresentam a noção de deformação da nuvem eletrônica em suas respostas. Especificamente, o termo polarizabilidade foi usado em apenas cinco respostas na questão 2 (9\%).

"Devido ao dipolo instantâneo/ induzido a nuvem eletrônica do $\mathrm{O}_{2}$ se distorce e ele se torna um pouco solúvel em água." (A10-Q1)

"Pelo $\mathrm{O}_{2}$ e o $\mathrm{CO}_{2}$ serem gases apolares, não seria esperado que fossem solúveis em água, porém a água, por apresentar grande momento de dipolo, pode influenciar moléculas apolares a adquirirem um momento de dipolo instantâneo, devido a alteração causada na nuvem eletrônica da substância apolar. A magnitude dessa alteração depende do momento de dipolo da molécula polar e da polarizabilidade da substância apolar." (A37 - Q2)

Outra justificativa expressa pelos estudantes refere-se à indicação que o fenômeno da solubilidade não depende exclusivamente das interações soluto-solvente, mas também das interações entre solvente-solvente e soluto-soluto como pode ser visto nas respostas de A30 e A41. No entanto, o último mencionado comete um equívoco ao indicar a existência de ligações de hidrogênio entre os solutos e a água, além de dipolo-dipolo induzido. Esse tipo de justificativa apareceu apenas em sete respostas da questão 2. Consideramos aqui, esse tipo de explicação que procura levar em conta as interações soluto-soluto, solvente-solvente e soluto-solvente, um esquema explicativo mais completo e correto para o processo.

"A água é uma molécula com grande momento de dipolo e possui interações do tipo ligação de hidrogênio, portanto possui pequena afinidade por substâncias que possuem interações dipolo-induzido $\left(\mathrm{CO}_{2}\right.$ e $\left.\mathrm{O}_{2}\right)$ tornando pequena a solubilidade dessas em água." (A30 - Q2)

" $\mathrm{O} \mathrm{O}_{2}$ e o $\mathrm{CO}_{2}$ dissolvem em água, pois formam ligações dipolo-dipolo induzido e algumas pontes de hidrogênio devido a existência de átomos de oxigênio em suas composições. Porém pouco dessas substâncias dissolvem-se em água, pois as ligações intermoleculares entre moléculas de água são mais fortes e energeticamente mais favoráveis que as entre a água e uma das outras substâncias.” (A41 - Q2)

\section{As representações das interações entre gás oxigênio e água expressas nos desenhos dos estudantes}

Nesse item da Q1 observou-se as representações elaboradas indicando as interações envolvidas em nível molecular. Para representar o processo completamente seria necessário expor os estados iniciais e finais das substâncias envolvidas, mas todas as respostas se limitaram ao estado final. O máximo a que se chegou foi a representação do processo de indução em si. Foram consideradas corretas ilustrações que mostravam ao menos a interação de um par de moléculas - gás oxigênio e água, ressaltando de alguma forma o dipolo molecular da água e a polarização do gás oxigênio. Também foi considerado se o item dissertativo da resposta estava correto.

Considerando as respostas dissertativas e as representações gráficas apresentadas na questão 1, 22 (49\%) dos investigados identificaram adequadamente a interação dipolo-dipolo induzido e representaram-na corretamente. Por outro lado, três conseguiram se expressar na forma escrita de maneira correta, porém, ao representar graficamente tiveram dificuldades; inclusive um desses estudantes não elaborou nenhuma representação. Outros dez identificaram e representaram incorretamente o tipo de interação. A questão foi deixada totalmente em branco por outros dez estudantes.

$\mathrm{Na}$ análise exclusiva das representações foram criadas categorias para os tipos de interação realçando algumas particularidades dos desenhos apresentados. No Quadro 3 são apresentados exemplos de desenhos feitos pelos estudantes que responderam na parte dissertativa que as interações entre oxigênio e água são do tipo dipolo-dipolo induzido. No Quadro 4 são expostos exemplos categorizados como equívocos que relataram interações do tipo ligações de hidrogênio, interações entre moléculas de oxigênio, ionização do oxigênio e forças dispersivas de London.

A grande maioria das representações só mostrou o sistema final não considerando as interações existentes entre soluto-soluto e solvente-solvente. Ao se referirem à existência de interações intermoleculares, foram usados traços pontilhados independentemente do tipo de interação ou as moléculas foram desenhadas próximas. Chama a atenção que o uso de traços pontilhados normalmente só é feito para as ligações de hidrogênio devido à proximidade com as ligações químicas e ao fato destas interações serem direcionais, porém, esses aspectos não foram tratados durante a disciplina e não são contemplados nos livros didáticos sugeridos no curso. Nos materiais didáticos a existência das interações comumente é sinalizada através da proximidade entre as moléculas, com exceção da ligação de hidrogênio, porém, a compreensão e diferenciação das representações deve ser feita pelo estudante, não são feitas menções ao longo do texto. No estudo de Galagovsky, Di Giacomo e Castelo também foi verificado em livros didáticos do ensino superior e em representações gráficas de docentes o uso da aproximação entre as moléculas para designar a ação de interações intermoleculares. ${ }^{17}$

De maneira geral, as representações submicroscópicas do fenômeno agrupadas nas categorias A, B e C do Quadro 3 não apresentaram erros estruturais ou conceituais significativos. Na categoria A foram classificados os desenhos que destacaram os momentos de dipolo da água e os momentos de dipolo induzidos das moléculas de oxigênio $\left(\mathrm{O}_{2}\right)$. Entretanto, sete estudantes mostraram apenas a interação entre duas moléculas enquanto outros quatro desenharam interações entre três ou mais moléculas. Alguns como A10 ainda não dominam o uso correto dos sinais $\delta^{+}$(polo elétrico) e + (carga elétrica), usando-os para o mesmo fim. Onze estudantes (categorias $\mathrm{B}$ e C) adicionaram em seus desenhos representações para as nuvens eletrônicas, o que denota a consideração de uma importante propriedade molecular envolvida, a polarizabilidade. Desses, sete estudantes (categoria B) ressaltaram em sua representação o processo em si, destacando a indução do dipolo na molécula de $\mathrm{O}_{2}$, enquanto quatro (categoria $\mathrm{C}$ ) representaram a molécula de $\mathrm{O}_{2}$ com a nuvem eletrônica já deformada e interagindo com moléculas de 
Quadro 3. Representações feitas pelos estudantes que na resposta dissertativa citaram as interações do tipo dipolo-dipolo induzido

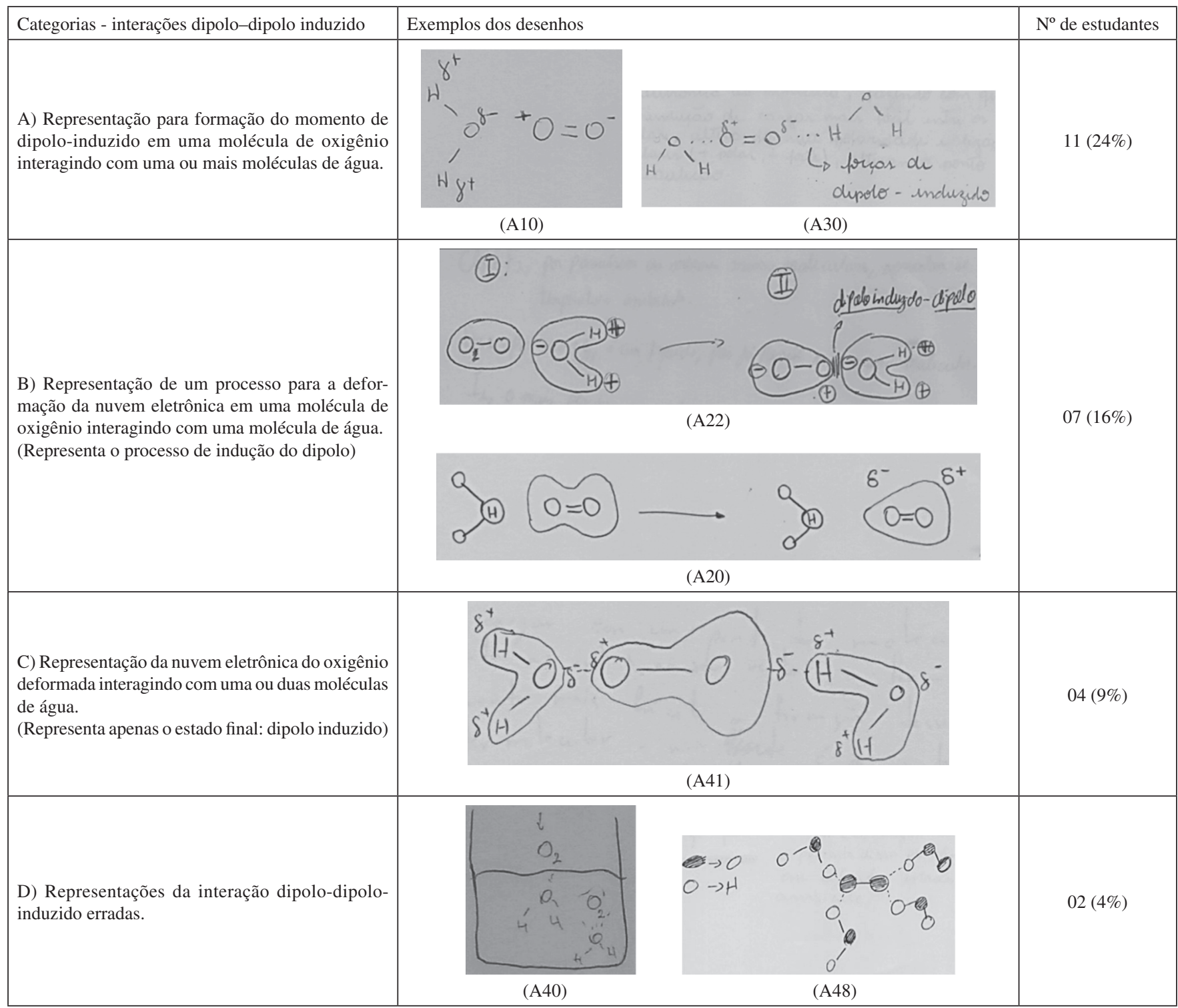

água, enfatizando assim, o estado final do sistema. O estudante A20 desenhou a molécula de água errada, mas representou o processo de distorção da nuvem eletrônica do oxigênio. Na categoria D, estão as representações equivocadas. Ao observar o desenho de A40 nota-se uma representação semelhante à que é comumente feita para a interação do tipo ligação de hidrogênio, porém, na resposta dissertativa o estudante respondeu: "As moléculas de água solvatam o $\mathrm{O}_{2}$ criando uma interação do tipo dipolo induzido”. O A48 misturou os níveis macroscópico e submicroscópico e não foi capaz de representar de maneira clara o tipo de interação envolvido. Nota-se aqui a importância de pedir para que os estudantes façam representações desse tipo ou que descrevam melhor e com mais detalhes o processo de interação. Um estudante pode fornecer uma resposta que o professor considere correta, mas, na verdade, pode não saber exatamente $o$ que significa quimicamente aquilo que respondeu.

No Quadro 4 são mostradas as representações equivocadas apresentadas por dez dos respondentes. Na categoria E são exibidos os desenhos que consideram as interações do tipo ligação de hidrogênio; três representaram interações entre oxigênio e hidrogênio. Ao comparar o número de respostas dissertativas categorizadas como ligação de hidrogênio (5) na questão 1 ao número de representações gráficas
(3) percebe-se a ausência de duas representações. Esse fato aconteceu porque A13, embora tenha respondido ligação de hidrogênio, fez um desenho mostrando apenas um átomo de oxigênio solvatado por moléculas de água estando inserido na categoria $\mathrm{G}$ - ionização da molécula de oxigênio. $\mathrm{O}$ estudante $\mathrm{A} 25$ também se referiu à existência de ligações de hidrogênio, porém, o seu desenho exibiu moléculas de gás oxigênio ocupando espaços entre as moléculas de água passando a integrar a categoria $\mathrm{H}$. Uma das respostas apresentou um desenho que mostrava apenas o processo de indução de momentos de dipolo entre as moléculas de gás oxigênio e não a interação desse com a água (categoria F). Na categoria $\mathrm{G}$ as duas representações indicam ionização das moléculas de oxigênio, porém, destaca-se que A46 mostrou que após a ionização ocorre a formação de uma nova substância ("O $\mathrm{O}_{2}$ se ioniza na água, gerando compostos polares"). $\mathrm{Na}$ categoria $\mathrm{H}$ são expostos os desenhos que inseriram as moléculas de oxigênio em espaços entre as moléculas de água. E, por fim, na categoria I a interação acontece por dipolos induzidos. Um átomo de oxigênio está interagindo com o oxigênio da água e o outro átomo de oxigênio interage com o hidrogênio da mesma molécula de água e não entre diferentes moléculas, ou seja, representa a interação apenas entre um par de moléculas. 
Quadro 4. Representações feitas pelos estudantes que na resposta dissertativa não citaram as interações do tipo dipolo-dipolo induzido

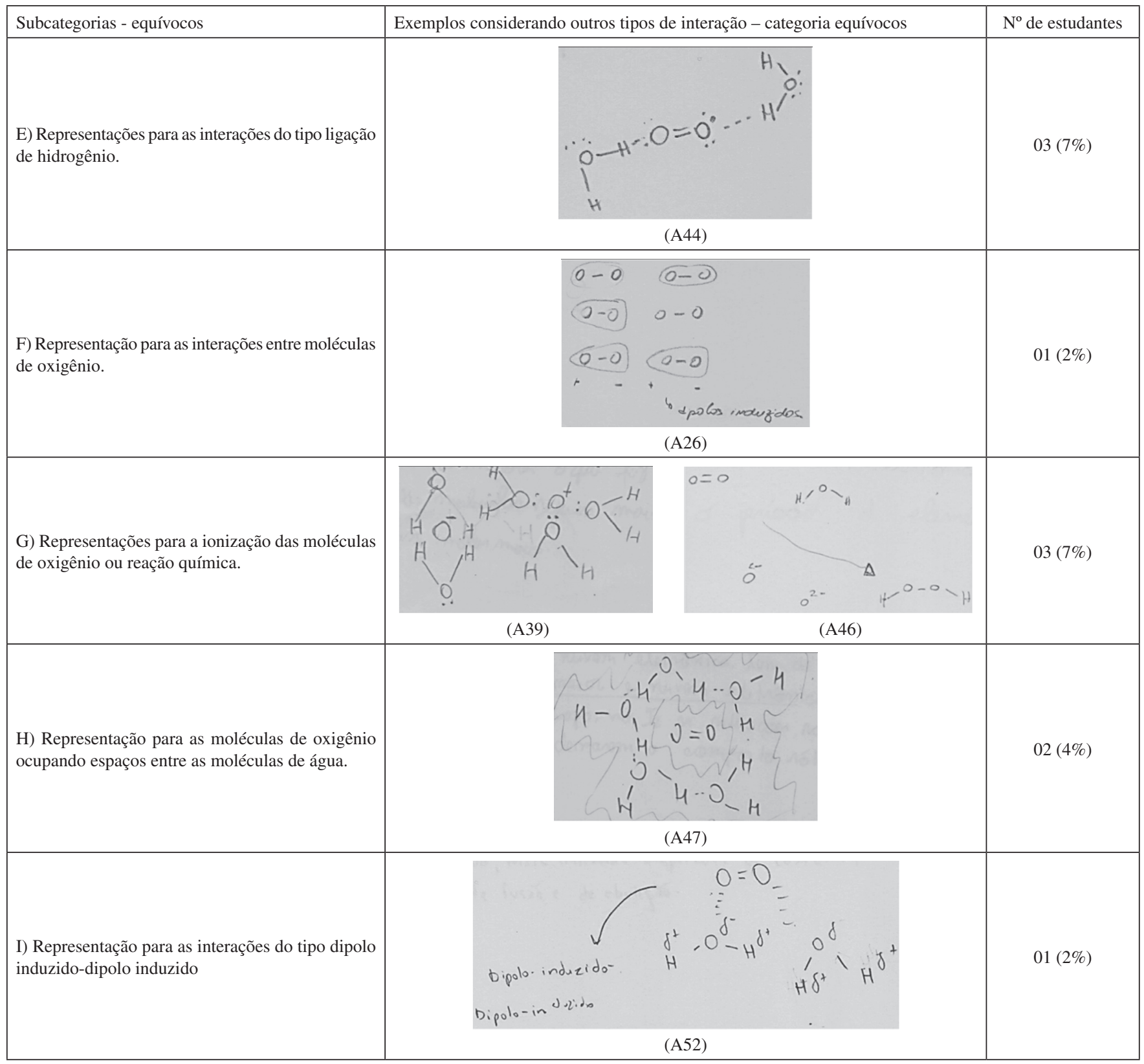

\section{Explicações para a solubilidade do gás oxigênio e dióxido de carbono em perfluorocarbonos}

Nesse item a resposta qualitativa mais completa consiste em realizar uma comparação dos processos interativos envolvidos para que ocorra a solubilidade nos sistemas: I) água e gases, e II) perfluorocarbonos e gases. No sistema I, antes da dissolução, as moléculas de solvente interagem através de ligações de hidrogênio, consideradas interações fortes; pode-se considerar que as moléculas dos gases, solutos, não interagem entre si; após a dissolução, as moléculas de soluto interagem com as moléculas de solvente através de interações do tipo dipolo-dipolo induzido. Esse processo não é muito favorecido, pois ocorrerá uma troca de interações fortes entre solvente-solvente por interações bem mais fracas entre soluto-solvente. No sistema II, antes da dissolução, as moléculas do solvente interagem por meio de interações dispersivas de London; as moléculas dos gases não interagem; após a dissolução, as interações soluto-solvente também são interações dispersivas, o que não gera uma variação grande de energia nas interações durante o processo de dissolução. Desse modo, a solubilidade no sistema II é maior se comparada ao sistema I. Todavia, observando o programa da disciplina (não mostrado aqui) e as aulas gravadas, observa-se que não foram feitas discussões profundas envolvendo solubilidade, o que acabou levando ao uso extensivo desses do esquema semelhante dissolve semelhante, largamente utilizado no ensino médio.

As respostas dos estudantes foram agrupadas em quatro categorias principais, sendo elas: I) a solubilidade do $\mathrm{O}_{2}$ e $\mathrm{CO}_{2}$ é maior em perfluorocarbonos do que em água porque esses gases e os perfluorocarbonos são substâncias apolares (19 - 36\%); II) a solubilidade é maior devido às interações dispersivas de London entre os gases e perfluorocarbonos (14 - 26\%); III) ocorrem interações dipolo-dipolo induzido entre os gases e perfluorocarbonos (11 - 21\%); IV) Outros - referem-se a oito respostas (15\%) que apresentaram ideias distintas entre si. Uma resposta foi deixada em branco. 
Na categoria referente à dissolução de substâncias apolares (categoria I), 19 estudantes justificaram a solubilidade enfatizando a regra semelhante dissolve semelhante ou a maior afinidade dos perfluorocarbonos.

" $\mathrm{O} \mathrm{O}_{2}$ e o $\mathrm{CO}_{2}$ possui uma maior solubilidade nos perfluorocarbonos, pois ambos são apolares (igual dissolve igual) ou menos polares que a água.” (A6 - Q2)

"Os perfluorocarbonos são substâncias apolares, devido a isso apresentam uma maior afinidade pelo $\mathrm{O}_{2}$ e $\mathrm{CO}_{2}$ do que a água, assim se conclui que os gases mencionados apresentam uma solubilidade maior nos perfluorocarbonos do que na água." (A37 - Q2)

Contudo, predizer que a solubilidade é determinada pela polaridade ou afinidade entre as substâncias não indica nenhuma compreensão do fenômeno em nível submicroscópico, como esperado para estudantes de um curso de química. O termo afinidade foi usado durante muitos anos para justificar a ocorrência de reações químicas, mas com o desenvolvimento de outras áreas seu uso foi deixado de lado, pois remetia ao "desejo" de uma substância atrair outra. ${ }^{18}$

Com relação às interações intermoleculares, 14 citaram a presença de interações dispersivas de London favorecendo a solubilidade, porém, novamente não foram encontradas justificativas que remetessem a uma compreensão em nível submicroscópico do fenômeno. De modo geral, acredita-se que a ideia 'semelhante dissolve semelhante' continua presente, só que ao invés de se referir a substâncias de mesma polaridade, indicam o mesmo tipo de interação intermolecular. Tratase de um algoritmo memorizado pelos estudantes que não requer uma profunda compreensão conceitual.

"A solubilidade do $\mathrm{O}_{2}$ e $\mathrm{CO}_{2}$ nos perfluorocarbonos é maior devido ao fato de ambos serem apolares, assim como as moléculas de $\mathrm{O}_{2}$ e de $\mathrm{CO}_{2}$. Com isso a interação entre essas moléculas se restrige a interações de London/ dispersão. Por conta da coincidência de interações intermoleculares, o $\mathrm{O}_{2}$ e o $\mathrm{CO}_{2}$ são muito mais solúveis em perfluorocarbonos do que em água, pois em água é necessário a indução de um dipolo.” (A27 - Q2)

A ocorrência de interações dipolo-dipolo induzido entre o oxigênio e os perfluorocarbonos foi explicitada por 11, porém, mais intensas do que no sistema com a água devido à eletronegatividade dos átomos de flúor. Nessas respostas os perfluorocarbonos são considerados substâncias com caráter polar, como exemplificado por A42. Aqui, os estudantes restringiram suas observações a um elemento químico específico e não analisaram a geometria molecular.

\footnotetext{
"Como podemos observar, os perfluorocarbonos possuem grandes quantidades de flúor (elemento mais eletronegativo), assim sendo ocorrem maiores quantidades de distorções e formam-se muito mais interações dipolo-dipolo induzido entre os gases $\mathrm{O}_{2}, \mathrm{CO}_{2}$ e os perfluorocarbonos do que com a água. Assim sendo a solubilidade de $\mathrm{O}_{2}$ e $\mathrm{CO}_{2}$ maior nos perfluorocarbonos do que na água." (A42 - Q2)
}

Na categoria "outros" cita-se, como exemplo, dois estudantes que comentaram a existência de ligações de hidrogênio nos perfluorocarbonos devido ao número de átomos de flúor; e outros dois estudantes mencionaram que a solubilidade é maior porque a geometria é favorável, mas não detalharam suas ideias.

\section{Explicações para a solubilidade do gás oxigênio em água doce e água salgada}

Para a discussão da solubilidade do gás oxigênio em água doce ou salgada pode-se levar em consideração o efeito salting out, no qual a adição de sais diminui a solubilidade de alguns compostos. ${ }^{19} \mathrm{Com}$ a solubilização de íons constituintes do sal, esses se ligam fortemente por interação íon-dipolo com um número expressivo de moléculas de água. Em altas concentrações de sal, menos moléculas de água estão disponíveis para interagir com o outro soluto, no caso $\mathrm{O}_{2}$, e, consequentemente, diminui sua solubilidade.

Ao analisar o fenômeno qualitativamente em nível submicroscópico devem-se considerar as interações intermoleculares que ocorrem nos sistemas formados por água - sais - gás oxigênio e água - gás oxigênio. No primeiro sistema ocorrem interações do tipo íon-dipolo entre a água e os sais, e interações dipolo-dipolo induzido entre a água e o gás oxigênio. As primeiras interações são mais intensas e prevalecem se comparadas as interações água - gás oxigênio, desse modo, na água salgada haverá uma menor disponibilidade de moléculas de água para interagir com as moléculas de oxigênio. Por outro lado, no segundo sistema as moléculas de água vão estar mais disponíveis para interagir com o gás oxigênio através de interações dipolo-dipolo induzido.

Nas respostas ao item verifica-se que 29 (55\%) julgaram ser maior a solubilidade em água salgada frente a 22 respostas $(42 \%)$ que escolheram como resposta a água doce (Quadro 5). Apenas 18 (34\%), além de escolherem a água doce, citaram que ocorre uma competição entre as interações água-íon e água-oxigênio, sendo a primeira mais forte, o que resulta em diminuição da solubilidade em água salgada. No entanto, desses, 4 identificaram equivocadamente os tipos de interações envolvidos e outros 4 indicam a competição, justificando corretamente, mas não mencionaram as interações intermoleculares (p. ex. A17)

“Água, pois na água salgada, parte das moléculas de $\mathrm{H}_{2} \mathrm{O}$ já são responsáveis pela solvatação dos íons que compõem o sal, restando um menor número de moléculas para solubilizar o $\mathrm{O}_{2}$." (A17 - Q2)

Apenas $10(19 \%)$ apresentaram uma justificativa mais completa de que na água salgada haverá uma competição entre interações dipolo-dipolo induzido entre água e oxigênio e íon-dipolo entre água e sais reduzindo a solubilidade do gás oxigênio. Resumindo, apenas 14 de 53 respostas $(26 \%$ ) podem ser consideradas corretas.

"Em água, pois a interação íon-dipolo é muito mais forte que a dipolo-dipolo induzido, assim a presença de sal na água diminui a disponibilidade da molécula de água para dissolver o $\mathrm{O}_{2} . "$ (A19 - Q2)

"Deve ser menos solúvel em água salgada, pois as interações entre as moléculas de água e $\mathrm{Na}^{+}$e $\mathrm{Cl}^{-}$são bem mais fortes que entre elas e os dipolos induzidos do gás. Por isso, as interações com o sal prevalecerão e as interações com o $\mathrm{O}_{2}$ diminuirão.” (A20 - Q2)

Por fim, um estudante escolhe a alternativa correta, mas justifica comparando a natureza dos tipos de interação em um esquema de pensamento que parece guiado pela regra "semelhante dissolve semelhante."

“Em água, pois na água salgada há a interação íon-íon, mais 'distinta' das forças de London presentes no $\mathrm{O}_{2}$, o que dificulta a solubilidade.” (A6 - Q2) 
Quadro 5. Categorias para a comparação da dissolução de gás oxigênio em água doce ou salgada

\begin{tabular}{|c|c|c|c|}
\hline Dimensão & Categorias & & $\begin{array}{l}\mathrm{N}^{\circ} \text { de estu- } \\
\text { dantes }\end{array}$ \\
\hline \multirow{5}{*}{ Água doce } & \multirow{3}{*}{$\begin{array}{l}\text { O gás oxigênio é } \\
\text { mais solúvel em } \\
\text { água doce porque } \\
\text { ocorre uma com- } \\
\text { petição entre as in- } \\
\text { terações água-íons e } \\
\text { água-oxigênio. }\end{array}$} & $\begin{array}{l}\text { Ao analisar conside- } \\
\text { raram as interações } \\
\text { intermoleculares: } \\
\text { água - íons (íon-di- } \\
\text { polo) e água - oxi- } \\
\text { gênio (dipolo-dipolo } \\
\text { induzido). }\end{array}$ & $10(18,5 \%)$ \\
\hline & & $\begin{array}{l}\text { Ao analisar consi- } \\
\text { deraram as intera- } \\
\text { ções intermolecu- } \\
\text { lares: água-íons e } \\
\text { água-oxigênio, } \\
\text { mas identificaram } \\
\text { equivocadamente } \\
\text { as interações água- } \\
\text {-oxigênio (ligação } \\
\text { de hidrogênio ou } \\
\text { dipolo-dipolo). }\end{array}$ & $4(7,5 \%)$ \\
\hline & & $\begin{array}{l}\text { Ao analisar não ci- } \\
\text { taram as interações } \\
\text { intermoleculares } \\
\text { envolvidas. Consi- } \\
\text { deraram que na água } \\
\text { salgada as moléculas } \\
\text { de água solvatam } \\
\text { os íons restando um } \\
\text { número reduzido de } \\
\text { moléculas para so- } \\
\text { lubilizar o gás oxi- } \\
\text { gênio. }\end{array}$ & $4(7,5 \%)$ \\
\hline & \multicolumn{2}{|c|}{$\begin{array}{l}\text { O gás oxigênio é mais solúvel em água doce, } \\
\text { mas justifica comparando as semelhanças } \\
\text { entre os possíveis tipos de interações. }\end{array}$} & $1(2 \%)$ \\
\hline & \multicolumn{2}{|c|}{$\begin{array}{l}\text { O gás oxigênio é mais solúvel em água doce } \\
\text { porque os íons presentes na água salgada } \\
\text { dificultam a solubilização. }\end{array}$} & $3(5,5 \%)$ \\
\hline \multirow{3}{*}{$\begin{array}{l}\text { Água } \\
\text { salgada }\end{array}$} & \multicolumn{2}{|c|}{$\begin{array}{l}\text { O gás oxigênio é mais solúvel em água } \\
\text { salgada porque os íons (cargas) deformam } \\
\text { intensamente as nuvens eletrônicas do } \\
\text { oxigênio. }\end{array}$} & $25(46,5 \%)$ \\
\hline & \multicolumn{2}{|c|}{$\begin{array}{l}\text { O gás oxigênio é mais solúvel em água sal- } \\
\text { gada devido a maior interação com os íons. }\end{array}$} & $3(5,5 \%)$ \\
\hline & \multicolumn{2}{|c|}{$\begin{array}{l}\text { O gás oxigênio é mais solúvel em água sal- } \\
\text { gada porque é possível um número maior de } \\
\text { reações químicas. }\end{array}$} & $1(2 \%)$ \\
\hline \multicolumn{3}{|l|}{ Em branco } & $2(4 \%)$ \\
\hline
\end{tabular}

Em outras três justificativas responderam apenas que a presença dos íons dificulta as interações entre o gás oxigênio e a água como pode ser observado nas respostas de A24 e A53. O estudante A53 também identificou a ocorrência de ligação de hidrogênio de modo errado.

"Na água. Pois os íons da água salgada aumentam a quantidade de cargas no meio, dificultando a formação do dipolo instantâneo e as interações dipolo permanente-dipolo induzido.” (A24 - Q2)

" $\mathrm{O} \mathrm{O}_{2}$ é mais solúvel em água, pois, em água salgada, há íons de sais livres que dificultam a interação das ligações de hidrogênio entre a água e o $\mathrm{O}_{2}$." (A53 - Q2)
As explicações para os que responderam que a maior solubilidade deve ser em água salgada apontaram majoritariamente (25) que nesse sistema haverá uma maior polarização das moléculas de $\mathrm{O}_{2}$. Nesse caso, $\mathrm{o} \mathrm{O}_{2}$ poderia ser polarizado tanto pelas moléculas de água quanto pelos íons presentes na água salgada, gerando um número superior de momentos de dipolo induzidos e interações mais intensas. As respostas A8, A21 e A36 ilustram esse raciocínio.

“ $\mathrm{O} \mathrm{O}_{2}$ deve ser mais solúvel na água salgada, já que os íons presentes nela também polarizam a molécula de $\mathrm{O}_{2}$. Mais polarizado o $\mathrm{O}_{2}$ pode se dissolver um pouco mais na água salgada." (A8 - Q2)

"É possível que, sob mesmas condições, $\mathrm{O}_{2}$ seja mais solúvel em água salgada, pois a presença dos íons (que inclusive apresentam fortes interações) pode facilitar a indução de dipolos no $\mathrm{O}_{2}$." (A21 - Q2)

"O oxigênio será mais solúvel em água salgada, devido a presença de íons solvatados na solução que criarão uma indução de distorção na nuvem eletrônica muito mais intensa que a água. Uma vez que, as interações intermoleculares iônicas são mais intensas do que as demais interações, inclusive as ligações de hidrogênio presentes nas moléculas de água." (A36 - Q2)

Por fim, três respostas simplesmente apresentam que na água salgada o gás oxigênio vai interagir com os íons presentes (p. ex. estudante A4) e um estudante (A34) mencionou que o oxigênio pode participar de reações químicas na água salgada.

"Mais solúvel em água salgada pelas interações com os íons presentes." (A4 - Q2)

"Deve ser mais solúvel em água salgada, pois esta tem mais elementos, os quais podem reagir, também, com oxigênio." (A34-Q2)

\section{DISCUSSÃO}

Após a categorização das respostas para cada item das questões, elaborou-se um quadro resumo (Quadro 6) com as características que foram mais recorrentes nas explicações ao considerar aspectos fundamentais para uma completa compreensão do fenômeno no nível submicroscópico. Essas características mais gerais possibilitaram algumas inferências sobre o raciocínio usado pelos estudantes e suas relações com as aulas e materiais didáticos.

Sobre os aspectos mais gerais das interações intermoleculares, chamou atenção o elevado número de respostas (56\%) que não usam ou aplicam o conceito de polarizabilidade nas explicações. Essa propriedade molecular é fundamental para a compreensão de interações intermoleculares que envolvem a formação de momentos de dipolos induzidos, interação importante presente em qualquer molécula, mesmo as polares. Entretanto, os dados sinalizam que essa ideia não foi apropriada pelos estudantes, mesmo tendo sido abordada durante as aulas.

Recorrendo-se às transcrições das aulas, pode-se verificar que o docente, na primeira aula do tema, expôs a propriedade molecular polarizabilidade durante explicações sobre as forças de dispersão de London definindo-a como a facilidade com a qual a nuvem de elétrons pode ser deformada. Antes de abordar a definição de polarizabilidade o docente já estava apresentando ideias envolvendo a deformação da nuvem eletrônica ao recordar função de distribuição radial e probabilidades relacionadas à localização dos elétrons. O docente levou um exemplo para discutir especificamente a dependência que as forças de dispersão de London têm com a polarizabilidade: 
Quadro 6. Características mais recorrentes nas respostas dos estudantes para o fenômeno da solubilidade

\begin{tabular}{|c|c|c|}
\hline DIMENSÕES & $\begin{array}{l}\text { Características recorrentes nas } \\
\text { explicações dos estudantes }\end{array}$ & $\begin{array}{l}\text { Número de } \\
\text { estudantes de um } \\
\text { total } 55\end{array}$ \\
\hline \multirow{3}{*}{$\begin{array}{l}\text { Aspectos gerais } \\
\text { sobre as inte- } \\
\text { rações intermo- } \\
\text { leculares }\end{array}$} & $\begin{array}{l}\text { Não usa os conceitos de polari- } \\
\text { zabilidade ou deformação da nu- } \\
\text { vem eletrônica nas explicações. }\end{array}$ & $30(56 \%)$ \\
\hline & $\begin{array}{l}\text { Determina incorretamente a } \\
\text { polaridade das moléculas. }\end{array}$ & $14(25 \%)$ \\
\hline & $\begin{array}{l}\text { Identifica incorretamente o tipo } \\
\text { de interação em diferentes con- } \\
\text { textos. }\end{array}$ & $25(45 \%)$ \\
\hline \multirow{2}{*}{$\begin{array}{l}\text { Generalização } \\
\text { da interação do } \\
\text { tipo ligação de } \\
\text { hidrogênio }\end{array}$} & $\begin{array}{l}\text { Sempre que há } \mathrm{H}, \mathrm{O}, \mathrm{F} \text { e } \mathrm{N} \text { ocorre } \\
\text { ligação de hidrogênio. }\end{array}$ & $13(24 \%)$ \\
\hline & $\begin{array}{l}\text { Sempre que há envolvimento } \\
\text { de água ocorre ligação de hi- } \\
\text { drogênio. }\end{array}$ & $13(24 \%)$ \\
\hline \multirow{4}{*}{$\begin{array}{l}\text { Fenômeno da } \\
\text { solubilidade }\end{array}$} & $\begin{array}{l}\text { O esquema algorítmico 'se- } \\
\text { melhante dissolve semelhante' } \\
\text { ajusta os dados e dificulta o } \\
\text { reconhecimento das possíveis } \\
\text { interações. }\end{array}$ & $27(49 \%)$ \\
\hline & $\begin{array}{l}\text { Não usa na explicação as dife- } \\
\text { rentes interações envolvidas no } \\
\text { fenômeno (soluto-soluto, sol- } \\
\text { vente-solvente e soluto-solvente) }\end{array}$ & $35(64 \%)$ \\
\hline & $\begin{array}{l}\text { Necessidade de ocorrência de } \\
\text { ionização ou dissociação para } \\
\text { solubilização em água. }\end{array}$ & $6(11 \%)$ \\
\hline & $\begin{array}{l}\text { Necessidade de ocorrência de } \\
\text { reação química para solubiliza- } \\
\text { ção em água. }\end{array}$ & $3(5 \%)$ \\
\hline $\begin{array}{l}\text { Representação } \\
\text { gráfica }\end{array}$ & $\begin{array}{l}\text { Dificuldade em representar grafi- } \\
\text { camente interações em diferentes } \\
\text { sistemas. }\end{array}$ & $13(24 \%)$ \\
\hline
\end{tabular}

Vamos pegar está série e a gente vai entender o que é polarizabilidade. A temperatura ambiente, flúor e cloro são gases, bromo é liquido e o iodo é um sólido [...]. Então porque que o iodo é um solido? Porque ele tem forças intermoleculares mais fortes [...]. Por que que a polarizabilidade do iodo é maior do que a do bromo? E é maior do cloro? Então a história é a seguinte, a polarizabilidade não é a facilidade de deformação da nuvem eletrônica? A nuvem eletrônica do iodo, não se encontra mais afastada dos núcleos de iodo na ligação covalente porque o iodo é maior? [...] Então o que é mais fácil você polarizar? Uma nuvem eletrônica que está mais longe dos núcleos ou mais perto dos núcleos? Mais longe, né. Então o iodo tem uma nuvem eletrônica mais flexível. Quando uma molécula de iodo vizinha cria um dipolo-induzido, este dipolo-induzido tem uma ação mais forte na outra nuvem eletrônica. (Fala do docente - transcrição da aula)

Durante a segunda aula as forças de dispersão de London foram revisadas e a definição da propriedade molecular polarizabilidade foi retomada e exposta novamente usando o exemplo da aula anterior. Em seguida, as interações dipolo-dipolo induzido foram descritas e apresentadas através do exemplo da solubilidade do gás oxigênio em água.

Em um dos materiais didáticos sugeridos no curso, a polarizabilidade é inicialmente tratada ao apresentarem correções para o modelo iônico indicando que as ligações iônicas têm algum caráter covalente, no sentido em que:

as cargas positivas de um cátion atraem os elétrons do ânion distorcendo a nuvem eletrônica esférica do ânion. Essa distorção pode ser entendida como uma tendência do par de elétrons se deslocar para a região entre os núcleos e formar uma ligação covalente. As ligações iônicas adquirem progressivamente maior caráter covalente quando a distorção da nuvem eletrônica do ânion aumenta. (2012, p.78) ${ }^{20}$

Em seguida é feita uma relação entre o volume dos átomos e íons e a polarizabilidade, mostrando que quanto mais volumoso, mais polarizável. A propriedade molecular polarizabilidade é retomada ao apresentarem as forças de London. É dada atenção para o modelo de distribuição dos elétrons em uma molécula não polar, ou em um átomo isolado; nesses casos os elétrons parecem estar simetricamente distribuídos, porém, em determinados instantes as nuvens de elétrons não são distribuídas uniformemente, gerando regiões com cargas parciais. Esses momentos de dipolos instantâneos podem distorcer a nuvem de elétrons de uma molécula vizinha dando origem às interações de London ou dipolo induzido-dipolo induzido. A energia dessas interações é dependente da polarizabilidade das moléculas, definida novamente como a facilidade de deformação das nuvens de elétrons. As interações dipolo-dipolo induzido são abordadas no mesmo tópico das forças de London por serem consideradas fortemente relacionadas. ${ }^{20}$

No segundo material didático, a polarizabilidade é mencionada logo após a apresentação da interação dipolo-dipolo induzido como "a extensão com que a nuvem eletrônica de um átomo ou molécula pode ser distorcida para induzir um dipolo depende da polarizabilidade do átomo ou da molécula" (2010, p.524). ${ }^{21}$ Nesse trecho da obra, a polarizabilidade é relacionada à massa molecular: quanto maior a massa molecular, maior a nuvem eletrônica e maior a polarizabilidade da molécula. Destaca-se que não foram encontradas referências à propriedade molecular polarizabilidade em outros fragmentos de texto da obra ao se fazer buscas no índice remissivo, sumário e leitura de várias páginas que abordam assuntos relacionados.

Constatar que um conceito como o de polarizabilidade estava presente nos livros didáticos, foi tratado pelo professor e, porém, quase não foi assimilado pelos estudantes, no sentido de compreender sua centralidade no processo de indução de uma interação intermolecular, não deve levar a que se responsabilize os estudantes pelo não aprendizado. O conceito certamente é novo para eles, uma vez que geralmente não é tratado no ensino médio, fato que deve ser questionado. A exposição ao processo de formação de dipolos induzidos em uma ou duas aulas, mesmo com o estudo em materiais didáticos (evidente que aqui não se pode garantir que todos os estudantes tenham estudado os textos), mostra-se que não é tão eficiente para um aprendizado efetivo. Antes de culpar os estudantes, deve-se ter em conta que o aprendizado nunca é imediato. Exige um contato continuo com o conteúdo e leva tempo. No caso em questão, sobre o conceito de polarizabilidade e o processo de interações dispersivas, os dados apresentados indicam apenas que pode ser interessante ressaltar mais esse tópico na disciplina de Química Geral e, mais ainda, retomar este tema em disciplinas futuras, apresentando-o em novas situações. Em resumo, é preciso que o professor universitário tenha claro essa realidade sobre o aprendizado e, diante dela, repensar o processo de ensino comumente aplicado.

Outro aspecto que chamou atenção em $25 \%$ das respostas está relacionado à determinação incorreta da polaridade de moléculas, tema tratado com exaustão durante as aulas e nos livros didáticos. Tal fato foi verificado principalmente no caso da solubilidade em 
perfluorocarbonos, possivelmente pela presença nas moléculas do elemento químico flúor, que possui elevada eletronegatividade. Provavelmente, os estudantes se detiveram à presença de um elemento químico para a determinação da polaridade e não consideraram, por exemplo, a geometria da molécula.

A presença do elemento químico flúor também acabou levando alguns (24\%) a identificarem ligações de hidrogênio entre as moléculas de perfluorocarbonos e gás oxigênio. Há relatos de outros trabalhos realizados com estudantes universitários em que eles também identificam as ligações de hidrogênio pela simples presença de átomos de flúor, oxigênio ou nitrogênio. ${ }^{22}$ Sabe-se que as ligações de hidrogênio são evidenciadas quando o hidrogênio se encontra entre os elementos químicos mencionados, ligado covalentemente a um elemento e interagindo através de uma interação intermolecular com o outro elemento. Mas essa informação acaba sendo suprimida e esquecida devido à ênfase dada a presença de átomos de flúor, oxigênio e nitrogênio em uma molécula.

Também houve identificação de ligação de hidrogênio em algumas situações devido à presença de água. Muitas abordagens envolvendo ligações de hidrogênio são ilustradas com a água, inclusive pode ser verificado nos materiais didáticos sugeridos no curso. Como exemplo, no livro de Kotz, Treichel e Weaver, é apresentado um item sobre a ligação de hidrogênio e as propriedades incomuns da água logo após as explicações gerais sobre as ligações de hidrogênio. ${ }^{21}$ Realmente essas interações são responsáveis por várias propriedades da água, um solvente muito utilizado na química, mas as ligações de hidrogênio também podem ser encontradas em vários outros sistemas. Ao longo das aulas também houve uso constante da água nas exemplificações.

A identificação correta dos tipos de interação intermolecular ainda não foi dominada por vários estudantes (45\%) em diferentes contextos, principalmente pela identificação constante de ligação de hidrogênio nos sistemas ou uso irrestrito de regras. De modo geral, os respondentes não conseguiram se apropriar do tema interações intermoleculares para explicar a diferença de solubilidade de gases apolares em água e nos perfluorocarbonos. Houve, por exemplo, uso extensivo da regra 'semelhante dissolve semelhante' ou 'igual dissolve igual' em $49 \%$ das respostas, apontando que esse esquema algorítmico ajusta os dados e dificulta o reconhecimento das possíveis interações. Ao observar os livros didáticos de química geral indicados na disciplina percebe-se que nas obras há referências diretas à regra 'igual dissolve igual', reforçando o seu uso. ${ }^{20,21}$ Porém, as semelhanças a serem observadas apresentam algumas distinções: em uma obra são enfatizadas as polaridades das moléculas e na outra os tipos de interações intermoleculares que são rompidas e formadas durante o processo de dissolução.

Podemos explicar a regra "igual dissolve igual" examinando as forças de atração entre as moléculas do soluto e do solvente. Quando o soluto dissolve em solventes líquidos, as atrações soluto-soluto são substituídas por atrações soluto-solvente e pode-se esperar dissolução se as novas interações forem semelhantes às interações originais. (p.345) ${ }^{20}$

Uma observação qualitativa em solubilidade é que "igual dissolve igual". Em outras palavras, moléculas polares provavelmente serão dissolvidas em um componente polar, $e$ moléculas apolares provavelmente serão dissolvidas em um componente apolar. A recíproca é verdadeira. $\left(2010\right.$, p.522) ${ }^{21}$

Nota-se que usualmente a escolarização e os materiais didáticos levam ao pensamento da semelhança, ou seja, o soluto precisa ter características próximas, similares às do solvente; somente nesta situação é que a solubilidade é possível. Destaca-se que o pensamento químico não deve estar restrito ao uso de regras, mas à compreensão qualitativa dos fenômenos no nível submicroscópico. É comum na Ciência a tendência por generalizações, por exemplo, as Leis científicas são um tipo especial de generalização. Em muitas ocasiões a regra "semelhante dissolve semelhante" pode funcionar. Mesmo químicos em seu trabalho diário fazem uso dela, por exemplo, quando estão a escolher um sistema de solvente numa separação cromatográfica. No entanto, o perigo é que a simplicidade de uma regra como essa pode levar a um uso acrítico da mesma. Por exemplo, encontramos em nossos estudos estudantes que justificam que clorofórmio e água não se misturam porque sendo a água sabidamente polar, o clorofórmio deve ser apolar, ${ }^{23}$ o que não corresponde à verdade. Desse modo, o fenômeno da solubilidade não deveria estar atrelado exclusivamente à regra 'semelhante dissolve semelhante', mas sim a uma abordagem dos processos e sistemas envolvidos, nos quais a natureza e energia das interações envolvidas são tidas em conta. Nesse caso específico, é preciso mudar a ênfase do pensamento dos estudantes que costuma considerar os estados das substâncias (a molécula de oxigênio é apolar, a água é apolar), para um pensamento que, ao considerar o processo químico em si, leva em conta os estados iniciais e finais dos sistemas envolvidos. ${ }^{1}$ No caso da dissolução envolve pensar que antes do processo há interações soluto-soluto e solvente-solvente, que devem ser rompidas para que no estado final se tenha interações soluto-solvente e solvente-solvente.

Vale lembrar que também é função da Universidade formar o professor do ensino médio. Se esse futuro professor desenvolve o pensamento descrito acima e o uso crítico de generalizações, podemos ter também um melhor resultado na educação básica.

Ao observar os livros didáticos sugeridos nota-se também que eles usam a solubilidade do gás oxigênio em água como exemplo da interação dipolo-dipolo induzido. Por exemplo, no livro de Kotz, Treichel e Weaver, as forças dipolo-dipolo induzido também são apresentadas através do exemplo da solubilidade do gás oxigênio em água:

Imagine uma molécula de água polar aproximando-se de uma molécula apolar como o $\mathrm{O}_{2}$. A nuvem eletrônica de uma molécula isolada (gasosa) de $\mathrm{O}_{2}$ é simetricamente distribuída ao redor dos dois átomos de oxigênio. Quando a extremidade negativa da molécula de $\mathrm{H}_{2} \mathrm{O}$ polar aproxima-se, entretanto, a nuvem eletrônica de $\mathrm{O}_{2}$ se torna distorcida. Nesse processo, a própria molécula de $\mathrm{O}_{2}$ torna-se polar, isto é, um dipolo é induzido, ou criado, na molécula de $\mathrm{O}_{2}$, inicialmente apolar. $\mathrm{O}$ resultado é que as moléculas de $\mathrm{H}_{2} \mathrm{O}_{2} \mathrm{O}_{2}$ são agora atraídas uma pela outra, embora apenas fracamente. O oxigênio pode dissolver-se em água porque existe uma força de atração entre um dipolo permanente e o dipolo induzido. Os químicos referem-se a tais interações como interações dipolo/ dipolo induzido. $(2010, \text { p.524) })^{21}$

Já no livro de Atkins e Jones (2012) não é apresentada uma explicação detalhada para a solubilidade do gás oxigênio em água, mas essa foi citada como exemplo de interação dipolo-dipolo induzido, mecanismo pelo qual uma molécula polar interage com outra não polar. ${ }^{20}$ No entanto, no capítulo específico de solubilidade as interações intermoleculares muitas vezes não são usadas explicitamente para explicar o fenômeno.

Observa-se, portanto, que os livros também não apresentam uma discussão mais profunda das interações rompidas e formadas durante o processo de dissolução que citamos acima. Também não enfocam a importância das propriedades moleculares polaridade e polarizabilidade, centrais neste processo, o que ajudaria na compreensão e assimilação das mesmas. 
Durante as aulas não houve uma preocupação em discutir o processo envolvido na solubilidade, foi enfatizado somente a interação soluto-solvente. Foi apresentada especificamente a solubilidade do gás oxigênio em água quando o docente exemplificou a interação dipolo-dipolo induzido. Nesse momento, foram ressaltadas a polaridade das moléculas envolvidas, a simetria da nuvem eletrônica e a polarizabilidade:

Muito bem vou pegar este caso aqui, dipolo permanentedipolo induzido. Então aqui o exemplo clássico da interação dipolo-dipolo induzido. O que que significa isso? Dipolodipolo induzido. Eu já tenho um dipolo numa molécula que é permanente e ele vai interagir com uma molécula que não tem dipolos, vai induzir um dipolo nessa molécula, é, apolar, tá certo. Então é o seguinte, ó, as vezes fica difícil entender porque iodo e oxigênio dissolvem em água, né, tá certo. Só que se a gente olhar a estrutura, é, olha o que acontece eu tenho a nuvem simétrica aqui do oxigênio, esta nuvem não é lá muito polarizável, só que é o seguinte é agora pela interação de um dipolo permanente com essas nuvens eletrônicas eu posso induzir um dipolo na nuvem eletrônica do oxigênio criando o que? Dipolo induzido, um dipolo instantâneo, tá certo. E qual é a grande, isso aqui tem uma consequência absurda disso aqui. Qual a consequência absurda disso aqui? Vida aquática né, tá certo, ok. [...] Muito bem, então este oxigênio a partir do momento que ele interage com a molécula, com um dos dipolos da molécula de água, ele se polariza e você tem a solubilização de oxigênio em água. Agora tem outra coisa também, certo, é o seguinte quando a gente fala, é, dissolve em água, lembrando o que eu to falando dissolve em água, eu to dizendo que dissolve. Eu to dizendo o quanto dissolve? Não né? Tá certo. O oxigênio é solúvel em água? Sim. É muito solúvel em água? Não, tá certo, ok? Essencialmente oxigênio é uma molécula apolar, tá certo, um pouco de oxigênio se dissolve em água. (Fala do docente - transcrição da aula - grifo nosso.)

Como já dito anteriormente, a identificação do tipo de interação intermolecular existente entre um soluto e um solvente é condição necessária para a compreensão do fenômeno da solubilidade, porém, não suficiente. Assim, a aula também não apresentou o processo de dissolução de forma completa como propomos anteriormente, avaliando os tipos de interações existentes entre as partículas do soluto e do solvente entre si, de maneira a que se desenvolva nos aprendizes um esquema de pensamento que leve em conta o processo total e não apenas o estado final do sistema, ou seja, um pensamento que ressalte o processo e não o estado final. ${ }^{1}$

Observa-se que muitas vezes os estudantes compreenderam alguns conteúdos conceituais como dados na perspectiva de Pozo e Crespo. ${ }^{1}$ Os conteúdos conceituais referem-se àqueles saberes científicos estabelecidos e presentes nos programas disciplinares e manuais didáticos que, por sua vez, podem ser divididos em dados, conceitos e princípios. Os dados ou fatos são informações que afirmam ou declaram algo sobre o mundo e devem ser aprendidos literalmente, gerando uma reprodução exata, sem a necessidade de compreendê-los. Porém, uma coisa é conhecer um dado e outra é dar-lhe significado. Para tal, é necessário utilizar os conceitos de modo a explicar por que ocorre o fato e quais as suas consequências. Os conceitos são aprendidos estabelecendo relações com os conhecimentos já existentes e podem ser entendidos em diferentes níveis. Por fim, "os princípios ou conceitos estruturais são conceitos muito gerais, com um grande nível de abstração, e na maioria das vezes subjacentes à organização conceitual de uma área, apesar de nem sempre ser suficientemente explícitos" (2009, p.79). ${ }^{1}$ A exemplo, conceitos tais como equilíbrio, conservação e interação são princípios que atravessam todos os conteúdos da química. Considerando a necessidade de compreender os vários fenômenos que ocorrem na sociedade e não simplesmente memorizá-los, e no caso específico de futuros químicos que precisam compreender os processos que ocorrem em nível submicroscópico, a transmissão dos dados e a abordagem dos conceitos específicos não devem constituir um fim em si mesmo, mas um meio para a compreensão dos princípios que perpassam o conhecimento científico.

Nessa perspectiva, citam-se alguns exemplos da compreensão dos estudantes ao nível de dados: a) a água faz ligação de hidrogênio; b) uma molécula só pode interagir com outra através de um único tipo de interação intermolecular independentemente do sistema; c) a presença de átomos de flúor, oxigênio e nitrogênio determinam a presença de ligação de hidrogênio; d) uma molécula é polar quando apresenta átomos muito eletronegativos como o flúor; e) moléculas polares são solúveis em moléculas polares, ou moléculas apolares são solúveis em moléculas apolares; e f) a semelhança entre soluto e solvente que define a solubilidade. Esses conhecimentos conceituais acabaram sendo apreendidos de modo reprodutivo, literal, numa perspectiva de acumulação de dados sem visar uma compreensão mais efetiva do conhecimento químico.

A falta do uso da propriedade molecular polarizabilidade e a determinação incorreta da polaridade também apontam para uma compreensão apenas de dados ou fatos, uma vez que a maioria das respostas apresentadas não estabeleceu relações conceituais pertinentes e mais completas nas justificativas apresentadas aos processos de solubilidade. Por exemplo, quando o estudante afirma que o perfluorocarbono é polar porque tem átomos de flúor, que são muito eletronegativos e levam à formação de momentos de dipolo na molécula, demonstra que assimilou um fato: a presença de átomos eletronegativos implica na existência de um momento dipolar. O aprendizado conceitual já implica relacionar eletronegatividade atômica com geometria molecular (no caso a molécula é simétrica) com compreensão do próprio conceito de momento de dipolo.

Tradicionalmente, o ensino universitário e, na maioria dos casos, também o ensino médio, é caracterizado por aulas expositivas nas quais o professor apresenta definições conceituais, seleciona exemplos e aplicações. O estudante anota pontos da aula e fica com a tarefa de estudar o conteúdo usando textos didáticos e listas de exercícios. Pelas descrições das aulas e análise dos livros didáticos, as aulas aqui acompanhadas não foram diferentes. No entanto, os resultados apresentados mostram que, nessa abordagem tradicional, o aprendizado não é completo e tão eficiente.

A quantidade de conteúdo e a falta de estudos que objetivam analisar a aprendizagem no ensino superior devem estar na raiz deste problema, uma vez que, fica sob responsabilidade do estudante estudar, geralmente sozinho e sem muito auxílio. Por consequência, ele precisa assimilar uma grande quantidade de informação em pouco tempo, e muitas vezes na véspera da prova.

\section{CONCLUSÕES E IMPLICAÇÕES}

As interações intermoleculares podem ser consideradas como um princípio que perpassa o conhecimento químico permitindo a explicação e entendimento de vários fenômenos como a solubilidade. ${ }^{1}$ A partir dos resultados obtidos observou-se que ao menos $45 \%$ dos estudantes investigados apresentaram alguma dificuldade em usar e identificar corretamente as interações intermoleculares envolvidas no fenômeno, e quando identificam só apresentam as interações envolvidas entre soluto e solvente, deixando de lado a ideia de processos e sistemas. Nota-se também que um número muito pequeno de respostas relaciona a propriedade molecular - polarizabilidade 
- ou expressa uma noção de deformação da nuvem eletrônica nas justificativas e nos desenhos elaborados.

Os dados nos levam à suposição de que o ensino que tem se voltado a uma classificação sobre os tipos de interação intermolecular sem a análise de diferentes sistemas e exemplos tem colaborado para um aprendizado restrito de dados e fatos dificultando a compreensão dos conceitos. Nesse sentido, sugerimos que durante as aulas os estudantes tenham a oportunidade de resolver questões e problemas que propiciem a análise de diferentes sistemas permitindo identificar as diferentes interações envolvidas e como elas se efetivam. Que essas questões sejam seguidas de discussão dirigida pelo professor, em que ele ressalte o papel dos conceitos importantes, de como se dá o processo de dissolução analisando os sistemas envolvidos em seus estados iniciais e finais, e não só uma identificação do tipo de interação envolvido. Desse modo, a solubilidade e as interações intermoleculares poderiam ser abordadas de maneira explicita e completa nos materiais didáticos e nas aulas, estabelecendo relações mais significativas entre os conceitos envolvidos, de modo que a solubilidade suporte a compreensão dos conceitos relacionados as interações intermoleculares e vice e versa. Esse tratamento mais completo e profundo pode levar à construção de modelos explicativos mais lógicos e coesos, superando a utilização de regras que nem sempre funcionam e na verdade não explicam o fenômeno do ponto de vista submicroscópico.

Apontamos também como sugestão para o ensino incentivar a elaboração de representações submicroscópicas durante as aulas pelos estudantes, possibilitando que eles demonstrem suas ideias para que as principais dúvidas sejam discutidas, ampliando a possibilidade de entendimentos. A fim de desenvolver um pensamento químico que leve em conta o processo em si, é importante que na etapa seguinte o professor auxilie os estudantes a representarem as substâncias envolvidas em seus estados inicial, antes da dissolução, e final, após a solução ser formada.

Por fim, para um aprendizado conceitual mais eficiente propomos aqui que o professor procure selecionar bem o conteúdo e exemplos/processos que ilustrem as relações mais importantes entre os diferentes conceitos envolvidos. No caso da solubilidade, processos como os envolvidos em Q1 e Q2 devem ser objetos de ensino e não somente objetos de avaliação final. A abordagem em sala de aula deve, como já citado anteriormente, ressaltar o processo em si, através da comparação das interações existentes e as propriedades moleculares envolvidas (polaridade, polarizabilidade, etc.) entre as substâncias puras (estado inicial) e a mistura (estado final), ressaltando as forças ou valores energéticos envolvidos em cada estado. Assim, propicia-se o desenvolvimento de um esquema conceitual que leve em conta as interações soluto-soluto, solvente-solvente e soluto-solvente.

\section{REFERÊNCIAS E NOTAS}

1. Pereira, A. S.; Dissertação de mestrado, Universidade Federal de Mato Grosso do Sul, Brasil, 2010.

2. Pozo, J. I.; Crespo, M. A. G.; Aprendizagem e o ensino de ciências, $5^{\mathrm{a}}$ ed., Editora Artmed: São Paulo, 2009.

3. Taber, K. S.; Research in Science and Technological Education 1995, $13,87$.

4. Fernandez, C.; Marcondes, M. E. R.; Quim. Nova Esc. 2006, 24, 20.

5. Rocha, W. R.; Cad. Tematicos Quim. Nova Esc. 2001, 4, 31.

6. Tarhan, L.; Ayar-Kayali, H.; Urek, R. O.; Acar, B.; Research in Science Education 2008, 38, 285

7. Schmidt, H. J.; Kaufmann, B.; Treagust, D. F.; Chem. Educ. Res. Pract. 2009, 10, 265.

8. Peterson, R.; Treagust, D. F.; J. Chem. Educ. 1989, 66, 459.

9. Peterson, R. F.; Aust. J. Educ. Chem. 1993, 11.

10. Coll, R. K.; Taylor, N.; Research in Science and Technological Education 2001, 19, 171.

11. Martins, C. R.; Lopes, W. A.; Andrade, J. B.; Quim. Nova 2013, 36, 1248.

12. Para fins de comparação entre as questões 1 e 2 , neste trabalho não foram analisadas as explicações da dissolução do $\mathrm{CO}_{2}$ em água (item a da questão 2), uma vez que isso não foi perguntado na questão 1 . No caso dos perfluorocarbonos foram consideradas as justificativas para $\mathrm{O}_{2}$ e $\mathrm{CO}_{2}$ conjuntamente, uma vez que nenhum estudante deu explicações diferentes para os dois sistemas.

13. Fiorucci, A. R.; Filho, E. B. Quim. Nova Esc. 2005, 22, 10.

14. Bardin, L.; Análise de conteúdo, Edições 70: Lisboa, 2009.

15. Souza, K. A. F. D.; Cardoso, A. A.; Quim. Nova 2009, 32, 237.

16. Echeverría, A.R.; Quim. Nova Esc. 1996, 3, 5.

17. Galagovsky, L.; Di Giacomo, M. A.; Castelo, V.; Revista Electrónica de Enseñanza de las Ciencias 2009, 8, 1.

18. Justi, R. S.; Quim. Nova Esc., 1998, 7, 26.

19. Voet, D.; Voet, J. G.; Biochemistry, $1^{\text {a }}$ ed., Wiley: New York, 1990.

20. Atkins, P. W.; Jones, L.; Princípios de química: questionando a vida moderna e o meio ambiente, $5^{\mathrm{a}}$ ed., Bookman: Porto Alegre, 2012.

21. Kotz, J. C.; Treichel, P. M.; Weaver, G. C.; Química Geral e Reações

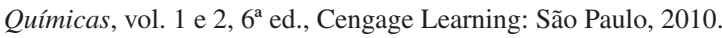

22. Smith, K. C.; Nakhleh, M. B.; Chem. Educ. Res. Pract. 2011, 12, 398.

23. Dados obtidos em entrevistas com estudantes de graduação em Química ainda não publicados. 